\title{
Ischemia Alters Cerebral Vascular Responses to Hypercapnia and Acetylcholine in Piglets
}

\author{
CHARLES W. LEFFLER, DAVID W. BUSIJA, WILLIAM M. ARMSTEAD, ROBERT MIRRO, AND \\ DONATHAN G. BEASLEY \\ Department of Physiology and Biophysics and Department of Pediatrics, University of Tennessee, Memphis,
}

Memphis, Tennessee 38163

\begin{abstract}
Effects of ischemia (20 $\mathrm{min})$ on cerebral cortical prostanoid synthesis and microvascular responses to hypercapnia and topical acetylcholine were examined in anesthetized newborn pigs. Pial arteriolar dilation in response to hypercapnia $\left(10 \% \mathrm{CO}_{2}\right.$ ventilation, $10 \mathrm{~min}$ ) was absent $2 \mathrm{~h}$ after ischemia and reversed toward constriction by $24 \mathrm{~h}$ postischemia. In sham control piglets, hypercapnia increased cortical periarachnoid fluid prostanoid concentrations. After ischemia, hypercapnia did not affect prostanoid concentrations on the brain surface. Acetylcholine $\left(10^{-3} \mathrm{M}\right)$-induced pial arteriolar constriction was reversed toward dilation $24 \mathrm{~h}$ after cerebral ischemia. Further, acetylcholine-induced prostanoid synthesis was markedly attenuated after ischemia. We conclude that cerebral ischemia-reperfusion alters cerebral prostanoid synthesis and microvascular control in newborn pigs. These abnormalities persist for at least 24 h. (Pediatr Res 25:180-183, 1989)
\end{abstract}

\section{Abbreviations \\ CSF, cerebral spinal fluid}

Cerebral ischemia and the following reperfusion results in damage that may alter cerebral vascular responses to changes in blood gases, blood pressure, and pharmacologic agents. Bursts of cyclooxygenase activity and generation of activated oxygen species can occur upon reperfusion after ischemia (1). Such bursts of cyclooxygenase activity and generation of activated oxygen species may compromise the prostanoid system. Compromise of the prostanoid system may contribute to alteration of vascular responses because prostanoids are important in the regulation of the cerebral vascular response of newborn pigs to various physiologic and pharmacologic stimuli (2).

Therefore, the present experiments are designed to address the hypothesis that cerebral ischemia attenuates stimulus-induced cerebral prostanoid synthesis and thereby alters both prostanoiddependent vasodilator (hypercapnia) (3) and prostanoid-dependent vasoconstrictor (acetylcholine) (4) responses.

\section{MATERIALS AND METHODS}

The surgical procedures and experimental protocols used were reviewed and approved by the Animal Care and Use Committee of the University of Tennessee, Memphis.

Received July 22, 1988; accepted October 11, 1988.

Correspondence Dr. C. W. Leffler, 894 Union Avenue (NA 427), Memphis, TN 38163 .

Supported by grants from the National Institutes of Health and the Tennessee Affiliate of the American Heart Association. W.M.A. is supported by a Postdoctoral Fcllowship from the Tennessee Affiliate of the American Heart Association, and R.M. is supported by a Clinical Investigatorship from the National Institutes of Health.
Production of total cerebral ischemia. Under halothane (1$3 \%)$ and nitrous oxide $(50 \%)$ anesthesia, hollow stainless steel bolts were implanted aseptically in the skulls of 1-day-old piglets. Catheters also were placed in the aortae via peripheral arteries for blood withdrawal and blood pressure monitoring. Then 3 days later, $20 \mathrm{~min}$ of total brain ischemia was produced by infusing artificial CSF into the hollow bolt to increase the intracranial pressures of mechanically ventilated, unanesthetized piglets $15 \mathrm{~mm} \mathrm{Hg}$ above mean arterial pressure. Arterial blood was withdrawn as necessary to prevent the Cushing response from raising mean arterial pressure higher than $100 \mathrm{~mm} \mathrm{Hg}$. Within $5 \mathrm{~s}$ of increasing intracranial pressure, all piglets were unresponsive to tactile and auditory stimuli, and their pupils were fixed and dilated. There was no evidence of pain or apparent awareness of the procedure before loss of consciousness. This procedure results in reduction of blood flow throughout the brain and spinal cord to levels that are not detectable using radioactively labeled microspheres. Spontaneous ventilation resumes after $30-$ $60 \mathrm{~min}$ of reperfusion.

Piglets were divided into three groups for examination of the pial microcirculation using closed cranial window techniques. Sham control animals were treated identically to those in the other two groups, except that intracranial pressure was increased to about $100 \mathrm{~mm} \mathrm{Hg}$ for only $1-2 \mathrm{~s}$ and then returned to control in half of the animals, or the bolt was inserted but intracranial pressure was not increased in the other half. Because data from these two groups of piglets were indistinguishable and consistent with our previous experiments on intact piglets, results from both groups were combined. In the second group of piglets $(2 \mathrm{~h}$ postischemia), surgery for implantation of the cranial window was begun after $50 \mathrm{~min}$ of reperfusion, allowing the microcirculatory studies to begin at $2 \mathrm{~h}$ of reperfusion. In the third group ( $24 \mathrm{~h}$ postischemia), the cranial window was implanted $24 \mathrm{~h}$ after the brain ischemia. These latter piglets were fed pig milk substitute by gavage, because they did not regain consciousness.

Cranial window implantation and experimental protocol. Newborn pigs were anesthetized with ketamine hydrochloride (33 $\mathrm{mg} / \mathrm{kg}$, intramuscularly) and acepromazine $(3.3 \mathrm{mg} / \mathrm{kg}$, intramuscularly) and maintained on $\alpha$-chloralose $(50 \mathrm{mg} / \mathrm{kg}$, intravenously initially, plus $10 \mathrm{mg} \cdot \mathrm{kg}^{-1} \cdot \mathrm{h}^{-1}$ ). The animals were intubated and ventilated with air. Catheters were inserted in the femoral vein for maintenance of anesthesia and, in some piglets, in the femoral artery to record blood pressure and draw samples for blood gas and $\mathrm{pH}$ analysis (in others, we used the catheters inserted when the bolt was placed). Body temperature was maintained at $37-38^{\circ} \mathrm{C}$ by wrapping the piglet in plastic film and a water-circulating heating pad. The scalp was retracted, and a hole $2 \mathrm{~cm}$ in diameter was made in the skull over the parietal cortex. The dura was cut without touching the brain, and all cut edges were retracted over the bone so that the periarachnoid space was not exposed to either damaged bone or damaged membranes. A stainless steel and glass cranial window was placed in the hole and cemented into place with dental acrylic. The space under the window was filled with artificial CSF $(150 \mathrm{mEq}$ 
$\mathrm{Na}^{+} /$liter; $3 \mathrm{mEq} \mathrm{K} /$ liter; $2.5 \mathrm{mEq} \mathrm{Ca}{ }^{++} /$liter; $1.2 \mathrm{mEq} \mathrm{Mg}^{++} /$ liter; $132 \mathrm{mEq} \mathrm{Cl}{ }^{-} /$liter; $3.7 \mathrm{mM}$ glucose; $6 \mathrm{mM}$ urea; $25 \mathrm{mEq}$ $\mathrm{HCO}_{3}^{-}$/liter; $\mathrm{pH} 7.33 ; 46 \mathrm{~mm} \mathrm{Hg} \mathrm{PCO} ; 43 \mathrm{~mm} \mathrm{Hg} \mathrm{PO}$ ) through needles incorporated into the sides of the window. The vol of fluid directly under the window was $500 \mu$ l and was contiguous with the endogenous CSF. After implantation of the window, 20 min were allowed for stabilization and equilibration of fluid under the window with the periarachnoid fluid before experimentation was begun.

Pial arterioles were observed with a trinocular stereomicroscope. Pial arteriolar diameter was measured with a television camera mounted on the microscope, a video monitor, and a video microscaler (model VPA-1000, FOR-A Corp., Los Angeles, $\mathrm{CA}$ ). Using a stage micrometer, we determined that the scale is linear over the range from $0-1000 \mu \mathrm{m}$.

Cerebral surface CSF ( $300 \mu \mathrm{l}$ of the $500 \mu \mathrm{l}$ under the window) was collected by placing a $1-\mathrm{ml}$ syringe on an injection port of the cranial window. CSF was collected by slowly infusing artificial CSF into one side of the window and allowing the CSF under the window to drip freely into a collection tube on the opposite side.

The experimental design consisted of measurements of pial arteriolar diameter, arterial pressure, arterial blood gases and $\mathrm{pH}$, and collection of cortical periarachnoid CSF. After the piglet had been allowed to stabilize for $20 \mathrm{~min}$, the window was flushed with artificial CSF, and 10 min later we collected $300 \mu \mathrm{l} \mathrm{CSF}$ from under the window. Then, hypercapnia was produced by ventilating the piglet with a $10 \% \mathrm{CO}_{2}, 21 \% \mathrm{O}_{2}, 69 \% \mathrm{~N}_{2}$ mixture, and pial arteriolar diameter and arterial pressure were measured. The CSF from under the cranial window was collected $10 \mathrm{~min}$ later for prostanoid analysis, and an arterial sample for blood gas and $\mathrm{pH}$ analysis was drawn. The ventilation mixture was returned to air, and the window was flushed with artificial CSF four times at 5-min intervals. At the end of a repeat 10-min control period, pial arteriolar diameter and arterial pressure were measured, and a CSF sample from under the cranial window was collected. Next, acetylcholine dissolved in artificial CSF $\left(10^{-3}\right.$ $M)$ was injected under the cranial window while measuring pial arteriolar diameter and arterial pressure. Then, 10 min later, after the final measurements of pial arteriolar diameter and arterial pressure were made, another collection of cortical periarachnoid CSF was made. A final arterial blood sample for blood gas and $\mathrm{pH}$ analyses was then drawn. The treatments were not applied in reverse order (i.e. acetylcholine, then hypercapnia), because the effects of hypercapnia upon the cerebral circulation reverse on removal of the stimulus, with no detectable lingering effects; after topical acetylcholine at $10^{-3} \mathrm{M}$, the general responsiveness of the cerebral vasculature seems to be diminished.

Prostanoid analysis. Prostanoids (6-keto-prostaglandin $\mathrm{F}_{1 \alpha}$, thromboxane $\mathrm{B}_{2}$, prostaglandin $\mathrm{E}_{2}$, and prostaglandin $\mathrm{F}_{2 \alpha}$ ) in cortical periarachnoid CSF were analyzed by RIA against an artificial CSF matrix as described previously (5). All unknowns were assayed at three dilutions, with parallelism between the unknown dilution curve and the standard curve required before the result was used. Sample dilutions used in the present study allowed analysis of prostanoid concentrations at 100-100,000 $\mathrm{pg} / \mathrm{ml}$. Previously, using this assay, we demonstrated large proportional increases in the prostanoids examined after topical application of arachidonic acid and more than $90 \%$ decreases in concentrations of all prostanoids examined in the cortical periarachnoid fluid after treatment with indomethacin in basal conditions and when stimulated with exogenous arachidonic acid (6). Our antibodies cross-react minimally (less than $1 \%$ ) with the other prostanoids studied in the present experiments and with other eicosanoids examined (arachidonic acid, 5-HETE, 12HETE, 15-HETE, $\mathrm{LTB}_{4}, \mathrm{LTC}_{4}, \mathrm{LTD}_{4}$, lipoxin $\mathrm{A}_{4}$, lipoxin $\mathrm{B}_{4}$, $\mathrm{PGD}_{2}$ ).

Statistical analyses. All values are presented as means \pm SEM. Comparisons between two populations were made using $t$ tests for paired observations. Comparisons among more than two populations used ANOVA followed by $t$ tests with Bonferonni correction. $p<0.05$ was required for inference that populations were different.

\section{RESULTS}

The arterial pressures and blood gases and $\mathrm{pH}$ in the three groups (sham control, $2 \mathrm{~h}$ postischemia, and $24 \mathrm{~h}$ postischemia)

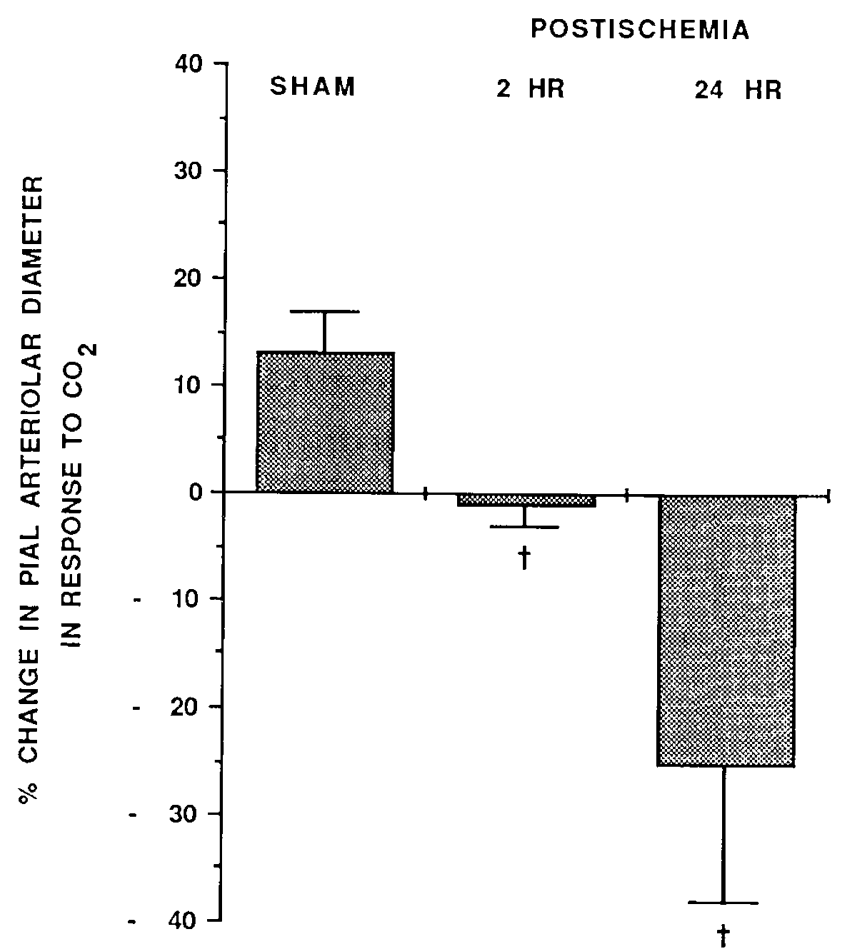

Fig. 1. Effects of ischemia upon pial arteriolar responses to hypercapnia in newborn pigs. Sham control, $n=13 ; 2$ h postischemia, $n=7 ; 24$ h postischemia, $n=6$. Values are means \pm SEM. $\S p<0.05$ compared to sham control.

Table 1. Response to hypercapnia

\begin{tabular}{|c|c|c|c|c|c|}
\hline & $\begin{array}{l}\text { Pial arteriolar diameter } \\
\qquad(\mu \mathrm{m})\end{array}$ & $\begin{array}{l}\text { Arterial pressure } \\
(\mathrm{mm} \mathrm{Hg})\end{array}$ & $\begin{array}{c}\mathrm{PaO}_{2} \\
(\mathrm{~mm} \mathrm{Hg})\end{array}$ & $\begin{array}{c}\mathrm{PaCO}_{2} \\
(\mathrm{~mm} \mathrm{Hg})\end{array}$ & $\begin{array}{c}\text { Arterial } \\
\mathrm{pH}\end{array}$ \\
\hline \multicolumn{6}{|l|}{ Control $(n=13)$} \\
\hline Normocapnia & $183 \pm 17$ & $56 \pm 2$ & $76 \pm 12$ & $34 \pm 1$ & $7.52 \pm 0.04$ \\
\hline Hypercapnia & $192 \pm 23^{*}$ & $55 \pm 5$ & $85 \pm 8$ & $62 \pm 1^{*}$ & $7.22 \pm 0.06^{*}$ \\
\hline \multicolumn{6}{|c|}{$2 \mathrm{~h}$ postischemia $(n=7)$} \\
\hline Normocapnia & $182 \pm 19$ & $46 \pm 3$ & $84 \pm 6$ & $37 \pm 2$ & $7.42 \pm 0.03$ \\
\hline Hypercapnia & $180 \pm 16$ & $43 \pm 4$ & $93 \pm 9$ & $64 \pm 2^{*}$ & $7.29 \pm 0.02 *$ \\
\hline \multicolumn{6}{|c|}{$24 \mathrm{~h}$ postischemia $(n=6)$} \\
\hline Normocapnia & $194 \pm 17$ & $52 \pm 3$ & $93 \pm 16$ & $33 \pm 2$ & $7.49 \pm 0.06$ \\
\hline Hypercapnia & $151 \pm 35$ & $43 \pm 5^{*}$ & $93 \pm 6$ & $54 \pm 5^{*}$ & $7.33 \pm 0.12^{*}$ \\
\hline
\end{tabular}

${ }^{*} p<0.05$ compared to normocapnia. 
were similar, although the arterial pressures in the two postischemic groups appeared to be reduced slightly (Table 1). Ventilation with the hypercapnic gas mixture increased arterial $\mathrm{PCO}_{2}$ and decreased arterial $\mathrm{pH}$ similarly in all three groups of piglets (Table 1).

Hypercapnia produced a typical cerebral arteriolar vasodilation in the sham control piglets (Table 1; Fig. 1). In contrast, hypercapnia produced minimal effects on pial arteriolar diameter $2 \mathrm{~h}$ postischemia and appeared to constrict pial arterioles $24 \mathrm{~h}$ postischemia (Table 1; Fig. 1).

During normocapnia, cortical periarachnoid CSF prostanoid concentrations were similar in sham control piglets and in piglets $2 \mathrm{~h}$ postischemia; however, concentrations were reduced at $24 \mathrm{~h}$ postischemia (Fig. 2). Hypercapnia caused an increase in cortical periarachnoid prostanoid concentrations in the sham control piglets (Fig. 2). However, the same degree of hypercapnia did not alter cortical periarachnoid CSF prostanoid concentrations either 2 or $24 \mathrm{~h}$ postischemia (Fig. 2).

Relatively high doses of acetylcholine $\left(10^{-3} \mathrm{M}\right)$ produced cerebral arteriolar vasoconstriction in the sham control piglets. In contrast, 2 and $24 \mathrm{~h}$ postischemia, acetylcholine failed to constrict pial arterioles (Fig. 3 ) and tended to produce ( $p=0.08)$ vasodilation $24 \mathrm{~h}$ postischemia (Table 2 ).

Acetylcholine increased cortical periarachnoid prostanoid concentrations nearly 18 -fold in the sham control piglets. In contrast, both 2 and 24 h postischemia, acetylcholine-induced prostanoid synthesis was attenuated markedly (Table 3 ).

\section{DISCUSSION}

Results of the present study demonstrate that interruption of cerebral blood flow for $20 \mathrm{~min}$ in newborn pigs produces grossly abnormal microcirculatory responses by $2 \mathrm{~h}$ of reperfusion. These altered responses persist or are accentuated $24 \mathrm{~h}$ later. Specifically, the prostanoid-dependent pial arteriolar vasodilation in response to hypercapnia $(3,5)$ is reversed toward constriction, and the prostanoid-dependent pial arteriolar constriction in response to topical acetylcholine $(4,7)$ is reversed toward dilation. Because the alteration of the prostanoid-dependent vascular responses occurs regardless of whether a dilator or constrictor response is involved, the effect of the ischemiareperfusion may be upon the prostanoid system, rather than directly upon responses to specific dilator or constrictor stimuli per se.

There are several possibilities by which the prostanoid system could be compromised by ischemia and/or reperfusion after ischemia. First, autoinactivation of cyclooxygenase (8) induced

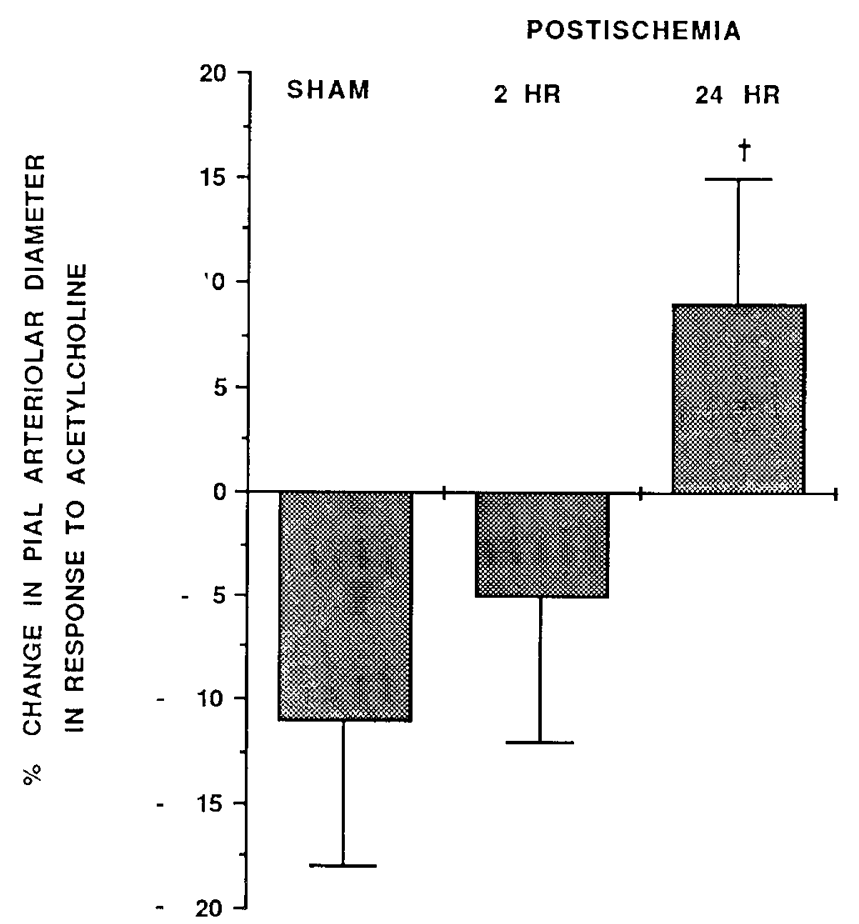

Fig. 3. Effects of ischemia upon pial arteriolar responses to acetylcholine $\left(10^{-3} \mathrm{M}\right)$ in newborn pigs. Sham control, $n=10 ; 2 \mathrm{~h}$ postischemia, $n=7 ; 24$ h postischemia, $n=5$. Values are means \pm SEM. $\S p<0.05$ compared to sham control.

Table 2. Response to topical acetylcholine $\left(10^{-3} \mathrm{M}\right)$

\begin{tabular}{lcc}
\hline & $\begin{array}{c}\text { Pial arteriolar diameter } \\
(\mu \mathrm{m})\end{array}$ & $\begin{array}{c}\text { Arterial pressure } \\
(\mathrm{mm} \mathrm{Hg})\end{array}$ \\
\hline $\begin{array}{l}\text { Control }(n=10) \\
\text { Vehicle }\end{array}$ & $157 \pm 14$ & $57 \pm 2$ \\
$\quad \begin{array}{l}\text { Acetylcholine } \\
\text { h postischemia }(n=7)\end{array}$ & $136 \pm 13^{*}$ & $58 \pm 2$ \\
$\quad$ Vehicle & $173 \pm 19$ & $46 \pm 3$ \\
$\quad$ Acetylcholine & $169 \pm 27$ & $43 \pm 2$ \\
24 h postischemia $(n=5)$ & $169 \pm 22$ & $58 \pm 2$ \\
$\quad$ Vehicle & $189 \pm 26$ & $55 \pm 4$ \\
$\quad$ Acetylcholine & & \\
\hline
\end{tabular}

${ }^{*} p<0.05$ compared to vehicle.

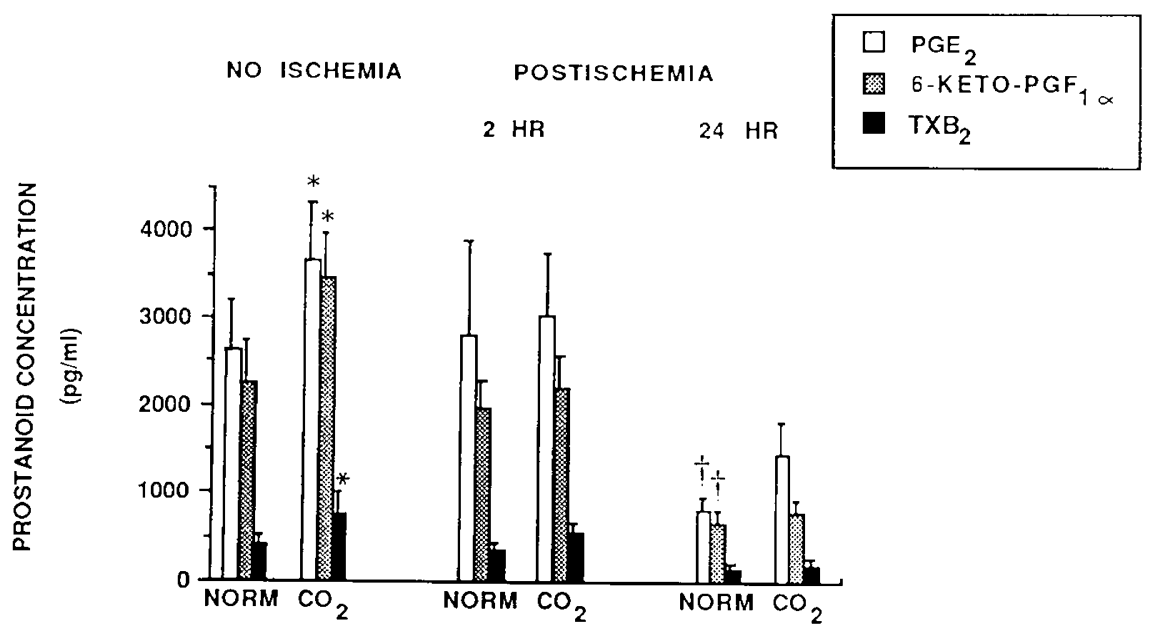

Fig. 2. Cortical periarachnoid CSF prostanoid concentrations during normocapnia $(N O R M)$ and hypercapnia $\left(\mathrm{CO}_{2}\right)$ in sham control (no ischemia) $(n=8), 2 \mathrm{~h}$ postischemia $(n=6)$, and $24 \mathrm{~h}$ postischemia $(n=5)$ newborn pigs. ${ }^{*} p<0.05$ compared to NORM. Values are means \pm SEM. $\S p<0.05$. POSTISCHEMIA NORM compared to NO ISCHEMIA NORM. 
Table 3. Cortical periarachnoid prostanoid concentrations

\begin{tabular}{|c|c|c|c|c|}
\hline & \multicolumn{4}{|c|}{ Prostanoid concentration $(\mathrm{pg} / \mathrm{ml})$} \\
\hline & $\mathrm{PGE}_{2}$ & 6-keto-PGF $F_{1 \alpha}$ & $\mathrm{PGF}_{2 \alpha}$ & $\mathrm{TXB}_{2}$ \\
\hline \multicolumn{5}{|l|}{ Control $(n=5)$} \\
\hline Vehicle & $1304 \pm 214$ & $1164 \pm 466$ & $994 \pm 629$ & $508 \pm 201$ \\
\hline $\operatorname{Ach}\left(10^{-3} \mathrm{M}\right)$ & $55,032 \pm 14,229 *$ & $6720 \pm 717^{*}$ & $5398 \pm 1707^{*}$ & $3145 \pm 1023^{*}$ \\
\hline \multicolumn{5}{|c|}{$2 \mathrm{~h}$ postischemia $(n=7)$} \\
\hline Vehicle & $2127 \pm 644$ & $1642 \pm 219$ & $1174 \pm 401$ & $298 \pm 57$ \\
\hline Ach $\left(10^{-3} \mathrm{M}\right)$ & $15,769 \pm 4915^{* \dagger}$ & $2401 \pm 521 \dagger$ & $2000 \pm 866$ & $260 \pm 82 \dagger$ \\
\hline \multicolumn{5}{|c|}{$24 \mathrm{~h}$ postischemia $(n=5)$} \\
\hline Vehicle & $1137 \pm 462$ & $487 \pm 128$ & $668 \pm 132$ & $196 \pm 80 \dagger$ \\
\hline $\operatorname{Ach}\left(10^{-3} \mathrm{M}\right)$ & $15,341 \pm 7297 * \uparrow$ & $3079 \pm 1758^{*}$ & $4896 \pm 2561^{*}$ & $622 \pm 248^{*} \dagger$ \\
\hline
\end{tabular}

$* p<0.05$ compared to vehicle.

$\dagger p<0.05$ compared to corresponding value in the sham control (control) group.

by a burst of cyclooxygenase activity upon reperfusion when high levels of free arachidonic acid would be expected $(9,10)$ could prevent later prostanoid synthesis. However, this possibility is unlikely because the effects persist at least $24 \mathrm{~h}$, by which time renewed active cyclooxygenase should be present. Second, we have found that activated oxygen is generated in large quantities at reperfusion, predominantly via cyclooxygenase-dependent mechanisms (1). Free radicals could damage cell membranes, enzymes, and nucleic acids. Third, alteration of many cellular components could occur during the ischemia period. The last two potential mechanisms could alter subsequent prostanoid synthesis by decreasing cyclooxygenase, decreasing arachidonic acid release by effects upon phospholipases, or by inhibiting stimulus-effector coupling.

The cause of the apparent constriction during hypercapnia subsequent to ischemia is unknown. It appears likely that the vasoconstrictor mechanisms that are normally attenuated by dilator prostanoids are capable of operating unopposed. One of the possible vasoconstrictor mechanisms is sympathetic nerve activity, which would be enhanced during severe hypercapnia (11). We have shown sympathetic stimulation constricts cerebral arterioles in piglets (12) and that indomethacin treatment augments vasoconstriction produced by topical norepinephrine (13). In addition, under certain circumstances that cause cerebral arterioles to dilate, we have found that vasopressin can produce constriction of pial arterioles (14).

Similarly, the apparent dilation observed in response to acetylcholine $24 \mathrm{~h}$ after ischemia is surprising. It is possible that ischemia does not damage endothelial cells sufficiently to prevent the release of endothelial cell-derived relaxing factor. If such were the case, acetylcholine-induced release of the endothelial cellderived relaxing factor (15) could produce a vasodilation that is unmasked when the overriding prostanoid-dependent vasoconstriction is removed. However, this explanation seems to be contradicted by the ability of indomethacin to abolish totally pial arteriolar responses to acetylcholine in normal piglets (4).

The abnormal responses we have observed in the pial microcirculation of newborn piglets in the postischemic period have potential clinical consequences for recovery after hypoxic-ischemic episodes. For example, failure of the cerebral circulation to dilate appropriately in response to subsequent episodes of asphyxia would result in severe cerebral tissue hypoxia and could produce further brain damage. Because the physiologic significance of acetylcholine in cerebral vascular control is poorly understood, the effects of an alteration in the response to this specific neurotransmitter are unknown.

In conclusion, we have found that cerebral ischemia-reperfusion produces abnormalities in microvascular control that persist for at least $24 \mathrm{~h}$. Stimulus-induced prostanoid synthesis is severely compromised and could be a mechanism by which microvascular control is lost.

We acknowledge the excellent technical assistance of D. Hardy, M. Jackson, L. Doti, T. Nilson, J. Giddens, and N. Leffler.

\section{REFERENCES}

1. Armstead WM, Mirro R, Busija DW, Leffler CW 1988 Postischemic generation of superoxide anion by newborn pig brain. Am J Physiol 255:H343-H346

2. Leffler CW, Busija DW 1987 Arachidonic acid metabolites and perinatal cerebral hemodynamics. Semin Perinatol 11:31-42

3. Wagerle LC, Mishra OP 1988 Mechanisms of $\mathrm{CO}_{2}$ response in cerebral arteries of the newborn pig: role of phospholipase, cyclooxygenase, and lipoxygenase pathways. Circ Res 62:1019-1026

4. Wagerle LC, Busija DW 1988 Cholinergic mechanisms in the cerebral circulation of the newborn piglet: effect of inhibitors of arachidonic acid metabolism. Circ Res (in press)

5. Leffler CW, Busija DW 1985 Prostanoids in cortical subarachnoid cerebrospinal fluid and pial artery diameter in newborn pigs. Circ Res 57:689-694

6. Leffler CW, Busija DW 1985 Arachidonate metabolism on the cerebral surface of newborn pigs. Prostaglandins 30:811-818

7. Busija DW, Pourcyrous M, Leffler CW, Wagerle LC 1988 Acetylcholine dramatically increases prostanoid synthesis in piglet parietal cortex. Brain Res 439:122-126

8. Needleman P, Turk J, Jakschik BA, Morrison AR, Lefkowith JB 1986 Arachidonic acid metabolism. Annu Rev Biochem 55:69-102

9. Abe K, Kogure K, Yamamoto H, Imazawa M, Miyamoto K 1987 Mechanism of arachidonic acid liberation during ischemia in gerbil cerebral cortex. J Neurochem 48:503-509

10. Wieloch T, Siesjo BK 1982 Ischemic brain injury: the importance of calcium, lipolytic activities, and free fatty acids. Pathol Biol (Paris) 30:269-277

11. Busija DW, Heistad DD 1984 Effects of activation of sympathetic nerves on cerebral blood flow during hypercapnia in cats and rabbits. J Physiol (Lond) 347:35-45

12. Busija DW, Leffler CW, Wagerle LC 1985 Responses of newborn pig pial arteries to sympathetic nervous stimulation and exogenous norepinephrine. Pediatr Res 19:1210-1214

13. Busija DW, Leffler CW 1987 Eicosanoid synthesis elicited by norepinephrine in piglet parietal cortex. Brain Res 403:243-248

14. Armstead WM, Mirro R, Busija DW, Leffler CW 1988 Vascular responses to vasopressin are tone-dependent in the cerebral circulation of the newborn pig. Circ Res (in press)

15. Furchgott RF, Zawadzki JV 1980 The obligatory role of the endothelial cells in the relaxation of arterial vascular smooth muscle by acetylcholine. Nature 288:373-376 